\section{Tolerance of Three Apple Cultivars to Ultra-low Levels of Oxygen}

\author{
O.L. Lau ${ }^{1}$ \\ Okanagan Federated Shippers Association, Kelowna, British Columbia, \\ V1Y 1J5, Canada
}

Additional index words. Malus domestica, postharvest physiology, low $\mathrm{O}_{2}$ injury

Abstract. Tolerance of apples to low levels ( $0.5 \%)$ of $\mathrm{O}_{2}$ was cultivar-dependent. 'Spartan' (SP), 'Delicious' (RD), and 'Golden Delicious' (GD) apples (Malus domestica Borkh.) held for 7 months in $1.0 \% \mathrm{O}_{2}$ (with $1.5 \% \mathrm{CO}_{2}$ ) at $0.5 \mathrm{C}$, plus $\approx 2$ months in air at $0 \mathrm{C}$ and 7 days in air at $20 \mathrm{C}$, were similar to those held in $1.5 \% \mathrm{O}_{2}$. However, incidence of skin injury in fruit held in $0.5 \% \mathrm{O}_{2}$ was very high in SP (purple-brown discoloration), low in RD (purple-brown discoloration), but only negligible in GD (lesions). Skin discoloration in SP and RD developed rapidly in air at $20 \mathrm{C}$. Holding in $0.5 \% \mathrm{O}_{2}$ improved retention of flesh firmness and juice acidity in GD and, under certain conditions, reduced scald in RD and SP, delayed yellowing in GD, but increased flesh breakdown in SP, flesh browning and alcohol flavor in SP and RD, and core browning in RD.

British Columbia-grown 'Golden Delicious' (GD), 'Delicious' (RD), and 'Spartan' (SP) apples kept well at $0 \mathrm{C}$ in a rapidly established $1.0 \% \mathrm{O}_{2}+1.0 \%$ to $1.5 \% \mathrm{CO}_{2}$ atmosphere (Lau, 1983, 1985). Anderson (1967) found that 'Delicious' apples stored for 6 months in $0 \% \mathrm{O}_{2}$ at $0 \mathrm{C}$ plus 7 days in air at $21 \mathrm{C}$ developed brown sunken skin injury, core browning, and fermented flavors. However, no fermented flavors and only negligible amounts of fruit injury occurred with atmospheres containing $1 \%$ or more $\mathrm{O}_{2}$. With commercial adoption of storage in $1.0 \%$ to $1.2 \% \mathrm{O}_{2}$ in the Pacific Northwest of North America, determination of whether atmospheres as low as $0.5 \% \mathrm{O}_{2}$ could be tolerated by the above cultivars and thus provide a margin of safety for packinghouse operators appeared appropriate. Storage results with $0.5 \%, 1.0 \%$, and $1.5 \% \mathrm{O}_{2}$ are discussed in this paper.

Box quantities ( 80 apples per box) of GD, $\mathrm{RD}$, and SP apples (33 lots per cultivar per $\mathrm{O}_{2}$ treatment per year, each one from a different grower, 1984 through 1986) were obtained randomly at controlled-atmosphere (CA) and air storage facilities in Oliver, Kelowna,

Received for publication 28 Dec. 1989. Appreciation is extended to Agriculture Canada Research Station, Summerland, B.C., for use of research facilities and to R. Yastremski for her capable assistance. The cost of publishing this paper was defrayed in part by the payment of page charges. Under postal regulations, this paper therefore must be hereby marked advertisement solely to indicate this fact.

'Correspondence address: Agriculture Canada Research Station, Summerland, B.C., Canada VOH $1 Z 0$. and Winfield, B.C., Canada, throughout the entire commercial harvest period. Flesh firmness, starch index, and internal ethylene concentration (IEC) of each grower lot were determined before storage (Table 1) on a 10fruit subsample using methods described previously (Lau, 1983; Lau et al., 1986). IEC values were used to calculate the percentage of fruit with IEC $>1 \mu l \cdot$ liter $^{-1}$ a value deemed indicative of the onset of fruit ripening.

The GD, RD (drenched in diphenylamine at $2000 \mathrm{mg} \cdot$ liter $^{-1}$ before storage), and SP samples were cooled in 0C air for 1.5 days before storage in $0.5 \% \mathrm{O}_{2}$ (cabinets; $0.85 \mathrm{t}$ ) or in $1.0 \%$ or $1.5 \% \mathrm{O}_{2}(\mathrm{CA}$ rooms; $420 \mathrm{t})$. The cabinets and rooms were maintained at $0.5 \pm 0.5 \mathrm{C}, \mathrm{O}_{2}$ values within $\pm 0.2 \%$, and $\mathrm{CO}_{2}$ at $1.5 \% \pm 0.2 \%$. The desired $\mathrm{O}_{2}$ and $\mathrm{CO}_{2}$ levels were established within 2 to 4 days and 3 days of sealing, respectively, and maintained by venting and lime scrubbing.

After CA storage plus a period in air at 0C and 7 days in air at 20C, subsamples of 10 to 15 apples from each treatment were assessed for flesh firmness and alcohol flavor (by a team of 11 sensory panelists, two panelists per grower replicate) as described previously (Lau, 1983). Incidence and severity of storage disorders were determined on 10-fruit (first and second examinations, Fig. 1) or 40-fruit samples (third examination, Fig. 1 and Table 2). Scores (maximum $=300$, Fig. 1 ) were derived by multiplying the severity ratings (slight $=1$, moderate = 2 , and severe $=3$ ) of the disorder by the percentage of fruit affected. Storage data were subjected to analysis of variance, and main effects sums-of-squares for storage $\mathrm{O}_{2}$ concentrations were partitioned into single-degrees-of-freedom polynomials. A quadratic response of quality characteristics to $\mathrm{O}_{2}$ concentrations is indicative of a parabolic relationship between fruit response and $\mathrm{O}_{2}$ concentrations.

GD, RD, and SP apples obtained from a wide range of orchards and maturities (Table 1) and held in $\leq 1.0 \% \mathrm{O}_{2}$ (with $1.5 \% \mathrm{CO}_{2}$ ) plus additional days in air at $0 \mathrm{C}$ and 7 days in air at 20C, were firmer and mostly higher in titratable acidity than comparable fruit held in $1.5 \% \mathrm{O}_{2}$ (Table 2). No appreciable increase in fruit injury was found in these three cultivars held in $1.0 \% \mathrm{O}_{2}$. In $0.5 \% \mathrm{O}_{2}$, however, the incidence of skin injury was very high in SP (discoloration), low in RD (discoloration), and only negligible in GD (lesions resembling those caused by high $\mathrm{CO}_{2}$ ) (Table 2). Post-CA storage of fruit for $\approx 2$ months in air at $0 \mathrm{C}$ increased the incidence, but not the severity, of skin discoloration in SP (Fig. 1). However, subsequent incubation of fruit for 7 days in air at 20C markedly increased the incidence and severity of the disorder in both RD and SP. Incidence and

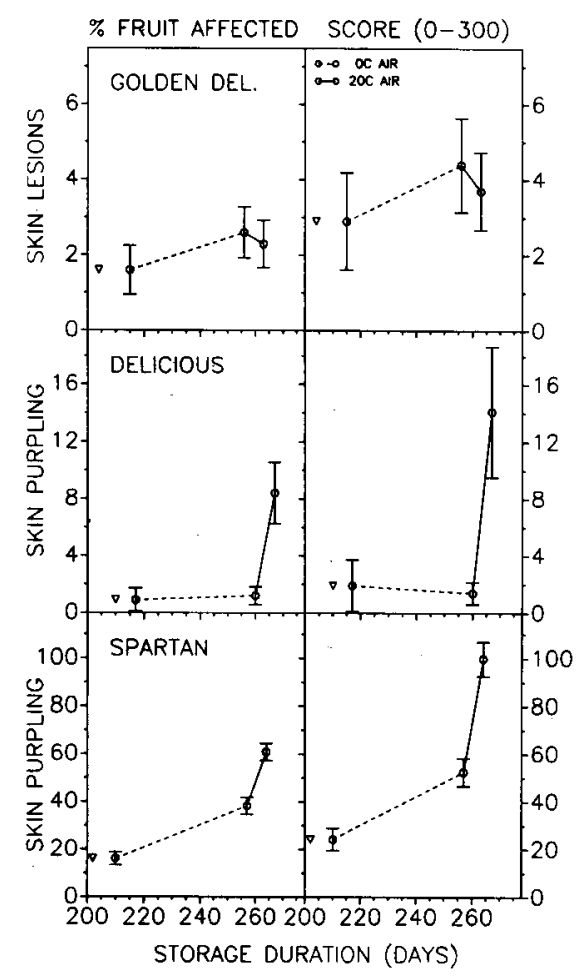

Fig. 1. Progression of skin lesions in 'Golden Delicious' and skin purple-brown discoloration in 'Delicious' and 'Spartan' apples after CA storage in air at $0 \mathrm{C}$ for 50 to 55 days (broken lines) and in air at $20 \mathrm{C}$ for 7 days (solid lines). Inverted triangles indicate the dates of fruit removal from storage at $0.5 \mathrm{C}$ in $0.5 \% \mathrm{O}_{2}+1.5 \%$ $\mathrm{CO}_{2}$. Vertical bars represent $\pm \mathrm{SE}(\mathrm{n}=33$ grower lots per year $\times 3$ ycars; 1984 through 1986). Note that scales differ for skin defects on y axis. 
Table 1. Characteristics of 'Golden Delicious', 'Delicious', and 'Spartan' apples at harvest $(\mathrm{n}=33$ grower replicates per year).

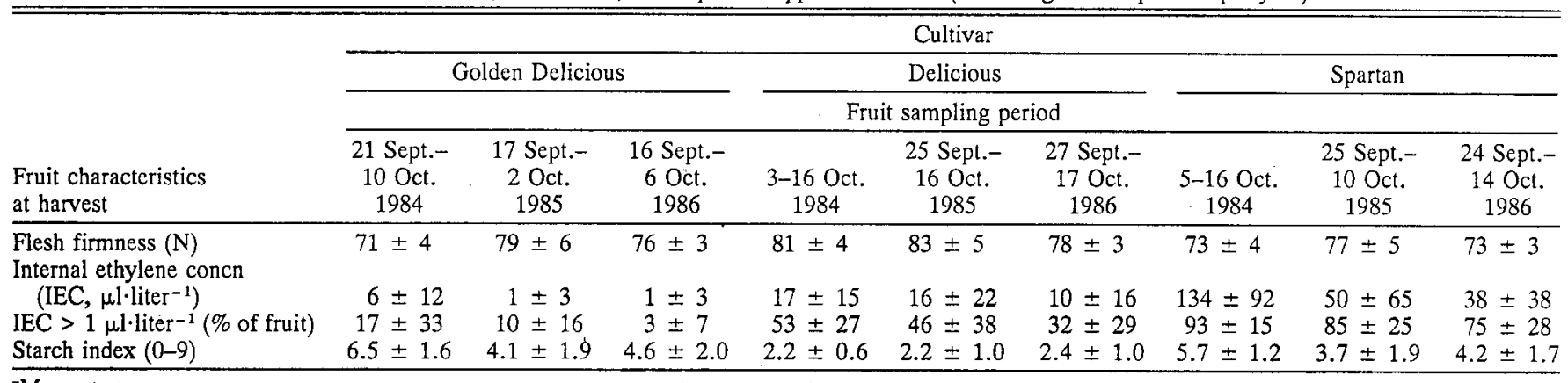

${ }^{2}$ Mean \pm SD.

Table 2. Effects of $\mathrm{O}_{2}$ concentrations (with $1.0 \% \mathrm{CO}_{2}$ at $0.5 \mathrm{C}$ ) on storage quality of 'Golden Delicious', 'Delicious', and 'Spartan' apples ( $\mathrm{n}=33$ grower replicates per cultivar per year).

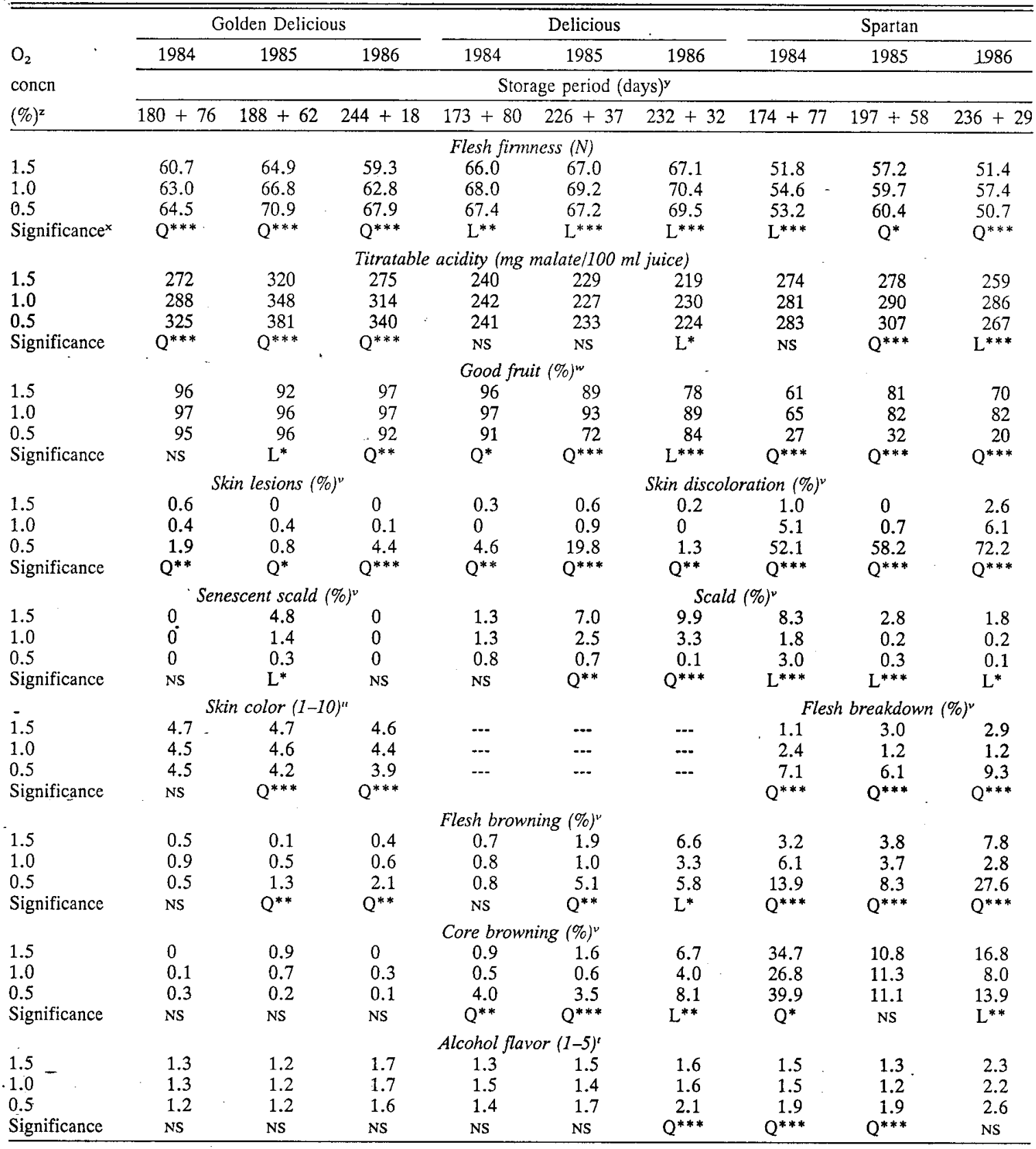

${ }^{2} \mathrm{Held}$ in 420 -t rooms $\left(1.5 \%\right.$ and $\left.1.0 \% \mathrm{O}_{2}\right)$ or 0.85 -t cabinets $\left(0.5 \% \mathrm{O}_{2}\right)$.

'Days in CA (first number) and air (sccond number) storage followed by a 7-day shelf life test in air at $20 \mathrm{C}$.

${ }^{x}$ Linear $(\mathrm{L})$, quadratic $(\mathrm{Q})$, and significant at $P=0.05\left(^{*}\right), 0.01\left(^{* *}\right)$, or $0.001\left(^{* * *}\right)$, or nonsignificant (NS).

wExpressed as percent of fruit without any fruit injury or storage disorder.

'Expressed as percent of fruit examined or affected (analysis of variance performed on arcsin square root of the percentage transformation).

"Higher values indicate less green pigment.

'Alcohol flavor: $1=$ none, $3=$ readily detectable, and $5=$ strong. 
severity of skin lesions in GD were not affected by the post-CA storage periods in air at 0 or $20 \mathrm{C}$.

Holding in $0.5 \% \mathrm{O}_{2}$ markedly improved retention of flesh firmness and juice acidity in GD and, in some years, reduced scald in RD and SP, delayed yellowing in GD, but increased flesh breakdown in SP, flesh browning and alcohol flavor in SP and RD, and core browning in RD. Varying tolerance of apple cultivars to $0.5 \% \mathrm{O}_{2}$ could be due to differences in their skin's resistance to diffusion and in their respiration rates (Cameron and Reid, 1982; Solomos, 1986).

In conclusion, GD was slightly more tolerant to $0.5 \% \mathrm{O}_{2}$ atmosphere than was $\mathrm{RD}$, which, in turn, was more tolerant than SP. While the margin of safety can be as much as $-0.5 \% \mathrm{O}_{2}$ for GD held in $1.0 \% \mathrm{O}_{2}$, indications (Lau, 1990) (Table 2) are that it is only $-0.3 \% \mathrm{O}_{2}$ for RD held in $1.0 \% \mathrm{O}_{2}$. Because of its low tolerance to $0.5 \% \mathrm{O}_{2}, \mathrm{SP}$ should be held at $\mathrm{O}_{2}$ levels $>1.0 \%$ at all times, preferably at $1.1 \% \pm 0.1 \% \mathrm{O}_{2}$.

\section{Literature Cited}

Anderson, R.E. 1967. Experimental storage of Eastern-grown 'Delicious' apples in various controlled atmospheres. Proc. Amer. Soc. Hort. Sci. 91:810-820.

Cameron, A.C. and M.S. Reid. 1982. Diffusive resistance: Importance and measurement in controlled atmosphere storage, p. 171-180. In: D.G. Richardson and M. Meheriuk (eds.). Proc. Third Natl. Controlled Atmosphere Res. Conf., Symp. Ser. 1, Oregon State Univ. School of Agr. Timber Press, Beaverton, Ore.

Lau, O.L. 1983. Effects of storage procedures and low oxygen and carbon dioxide atmospheres on storage quality of 'Spartan' apples. J. Amer. Soc. Hort. Sci. 108:953-957.
Lau, O.L. 1985. Storage procedures, low oxygen, and low carbon dioxide atmosphere on storage quality of 'Golden Delicious' and 'Delicious' apples. J. Amer. Soc. Hort. Sci. 110:541-547.

Lau, O.L. 1990. Control of storage scald in Delicious apples by diphenylamine, low oxygen storage, and ethylene scrubbing, p. 169-175. In: J.K. Fellman (ed.). Proc. Fifth Intl. Controlled Atmosphere Res. Conf., Wenatchee, Wash. vol. 1. Pome fruits.

Lau, O.L., Y. Liu, and S.F. Yang. 1986. Effects of fruit detachment on ethylene biosynthesis and loss of flesh firmness, skin color and starch in ripening 'Golden Delicious' apples. J. Amer. Soc. Hort. Sci. 111:731-734.

Solomos, T. 1986. Interactions between $\mathrm{O}_{2}$ levels, rate of respiration and gas diffusion in 5 apple varieties, p. 10-19. In: S.M. Blankenship (ed.). Proc. Fourth Natl. Controlled Atmosphere Res. Conf., Hort. Rpt. 126, North Carolina State Univ., Raleigh. 